\title{
E se insistem em perguntar Por que cantamos? ${ }^{1}$
}

\author{
Monique Lima
}

No Brasil, desde o ano de 2019 temos vivido um declínio generalizado das políticas públicas conquistadas e desenvolvidas nos anos anteriores (ainda que limitadas). Data de 17 de abril de 2016, exatamente vinte anos após o Massacre de Eldorado do Carajás, os 246 golpes contra o nosso esboço democrático, incluindo uma homenagem a um torturador, como faz questão de lembrar Maria Raimunda, dirigente do Movimento dos Trabalhadores Rurais Sem Terra - MST/Pará.

Na disputa da memória e na batalha das ideias, os anos de 2020 e 2021 têm sido cada vez mais sofridos, pois além da entrega do Estado e da falta de comprometimento com a maior parte da população brasileira, a crise sanitária provocada pela disseminação da Covid-19 tem agravado a nossa situação. Não me aterei aqui às propinas das vacinas ou à propaganda de drogas com ineficácia verificada à prevenção da Covid-19, produzidas pelo exército brasileiro e propagandeada por irresponsáveis, negligenciando cuidados efetivos, ou ainda, provando, pelo descaso para com as camadas menos assistidas, a arrojada dedicação aos empresários e latifundiários, mostrando a serviço de quem e para quem este governo "governa".

Escrevo em julho de 2021, num movimento de pautar a importância da memória pelas vidas perdidas, muito mais que CPFs cancelados como celebram alguns. Escrevo nos recentes dias de uma sociedade na qual se lamenta a estátua queimada de outro torturador histórico e que não se envergonha de perseguir as populações que se organizam por justiça social, atualizando e fazendo a manutenção opressora das classes dominantes. Escrevo no interior de uma sociedade que não se importa porque não investe em ciência, cultura e memória, como vimos recentemente com a queima dos servidores do $\mathrm{CNPq}$, o Conselho Nacional de Desenvolvimento Científico e Tecnológico, o novo incêndio na Cinemateca Brasileira, nos lembrando aquele descaso debochado do "pegou fogo, pegou"/"o que eu posso fazer?" de quando o Museu Nacional ardeu em chamas, em 2018, totalizando uma perda de 200 anos de instituição e de mais de 20 milhões de itens.

1 Conversa com o poema de Mário Benedetti, Por qué cantamos? Este texto contou com a leitura crítica e camarada do poeta Daniel Lage e da cineasta Natasha Rodrigues. Assino o texto, mas devo dizer que é expressão de sentimento partilhado com muitos outros corações e mentes. Às pessoas que seguem inspirando e incentivando este e outros escritos, meu sincero agradecimento. Sigamos! 
É inadiável compreender que o atual contexto político, econômico e cultural nos exige análises sócio históricas e que o movimento de uma sociologia militante é mais que imprescindível, inclusive por questões de sobrevivência coletiva. Preliminarmente, o meu objetivo com este texto é homenagear os que vieram antes de nós, também filhas e filhos do nosso tempo e que jamais partirão. É a partir dessas personalidades que este breve tributo é desenhado com vistas a ser estendido também às mais de 550 mil vidas e seus familiares.

Em tempo, é sempre bom lembrar que a conivência com esse Estado de destruição sepulta em vida, como desenhava Henfil na tirinha Cemitério dos Mortos-Vivos, aqueles e aquelas namoradinhas e namoradinhos do país que, dedicados ao lucro, ao poder, à promoção da mentira como verdade, jamais foram dignos do significado da palavra vida e, portanto, sequer merecem ter seus nomes citados: sabem muito bem quem são.

Para tecer esse rito de memória, selecionei alguns expoentes da cultura brasileira, como o compositor Aldir Blanc, a atriz Chica Xavier, o ator Flávio Migliaccio, o fotógrafo Januário Garcia e o artista, cineasta e professor universitário Sandro Lopes. Cabe dizer que este texto não investiga causa mortis: é uma singela homenagem. É a partir desse rito de exaltação às suas vidas e obras que movimento elementos a fim de contribuir com a urgente militância pela vida.

Na disputa das memórias e na batalha das ideias, algumas terminologias precisam ser definidas de acordo com as referências articuladas. Nesse sentido, situo que a memória é aqui compreendida como a vida, ou ainda, olhares sobre a experiência transcorrida e partilhada em um tempo de uma localidade, "sempre carregada por grupos vivos e, nesse sentido, ela está em permanente evolução, aberta à dialética da lembrança e do esquecimento", uma manifestação de "um elo vivido no eterno presente", portanto, memória como fenômeno que "instala a lembrança no sagrado" (Nora, 1993, p. 9).

O tempo, dessa maneira, não é uma ocorrência natural, mas compreendido como construções culturais influenciadas economicamente e socialmente por uma série de conjuntos relacionados em territórios situados politicamente. Ou seja, fruto das ações humanas e forjados historicamente por essas ações. Nesta perspectiva, portanto, a relação com o passado pode ser compreendida como "espaço de experiência", tendo a experiência como "o passado atual, aquele no qual acontecimentos foram incorporados e podem ser lembrados". Assim, o futuro pode ser lido como um "horizonte de expectativas", tendo expectativa como algo que "se realiza no hoje, é futuro presente", embebida de "esperança e medo, desejo e vontade" (Koselleck, 2006, p. 309). Localizo o debate também com Walter 
Benjamin quando convoca a "desfiar entre os dedos os acontecimentos", visando a "captar a constelação em que sua própria época entrou em contato com uma época anterior" (Benjamin, 2012, p. 252). Com esse preâmbulo, saudamos as vidas aqui reverenciadas.

“O temporal passou/ Restauram lama e lodo:/ Com isso é que Nanã/ Recria o mundo todo", das letras de Bença, Nã-Buruquê, o gigante legado de Aldir Blanc para a cultura brasileira transforma pelo abstrato das palavras, vidas que nos alimentam. Memoráveis aos ritmos das amizades, a sua Resposta ao tempo, nos desperta paixões que motivam as repetidas denúncias das violências do Estado brasileiro. Suas letras nos inspiram a nos posicionarmos, trajando luto como Carlitos, a provocar pelo riso, a fúria contra a miséria. Mas "uma dor assim pungente", Aldir, "não há de ser inutilmente", sabemos e não deixaremos que esqueçam "que o show de todo artista deve continuar".

Teatro, cinema, TV e literatura fazem parte da imensa atuação de Chica Xavier. A atriz soteropolitana iniciou a carreira nos anos de 1950 no Rio de Janeiro. Fez a Dama Negra, em Orfeu da Conceição, de Vinícius de Moraes (1954), no Teatro Municipal do Rio de Janeiro; O assalto ao trem pagador, de Roberto Farias, 1962. Laureada com o Troféu Palmares em 2010, acumula vasta produção em séries, novelas, teatro, cinema e também é tema da biografia Chica Xavier canta sua prosa. Cantigas, louvações e rezas para os orixás, por Teresa Montero (1999).

Nascido em bairro operário, Flávio Migliaccio integrou o TPE - Teatro Paulista do Estudante e o Teatro de Arena, em São Paulo. União que revoluciona a cena brasileira estreando nos palcos, a luta de classes, reinventando o país pela valorização da criação nacional, pela nova forma de pensar e fazer teatro. Atuou em clássicos como Eles não usam Black-Tie, de Gianfrancesco Guarnieri (1958), Chapetuba Futebol Clube, de Oduvaldo Vianna Filho (1959), Revolução na América do Sul, de Augusto Boal (1960), no filme A Hora e a Vez de Augusto Matraga (1965), de Roberto Santos, que tem Leonardo Villar no papel de Matraga. De atuação engajada, fez a voz do povo no Terra em Transe, de Glauber Rocha (1966).

“Na minha geração, ninguém vai poder falar que o negro não tem memória, porque vai ter. Eu vou fazer essa memória". A página do fotógrafo Januário Garcia apresenta seu enorme acervo: são capas de discos de grandes artistas da Música Popular Brasileira dos anos de 1970 e 1980, fotografias e exposições. ${ }^{2}$ Em resumo, mais de 100 mil fotos e documentos. Garcia foi presidente do IPCN - Instituto de Pesquisas das Culturas Negras, é autor de 25 anos do Movimento Negro (1980-2005), lançado em maio de 2008, no Museu da

2 Garcia, Januário: https://www.januariogarcia.com.br/ (Acessado: 01 Jul 2021). 
República/RJ; organizou o livro Histórias dos Quilombos do Estado do Rio de Janeiro (2002), entre outros. ${ }^{3}$ Formado em Comunicação Visual pela International Cameraman School, dedicou a sua vida e obra à luta antirracista e pela valorização da memória negra brasileira. Como registrado em sua fala no Cais do Valongo/RJ, Patrimônio Mundial pela Unesco: "existe uma história do negro sem o Brasil. O que não existe é uma história do Brasil sem o negro".

O artista, cineasta, pesquisador e professor Sandro Lopes nos marca pelo seu sorriso sereno e sua atuação precisa. Ilustrador e animador de grande contribuição para a educação antirracista, Sandro movimenta raízes profundas sonhando a infância do futuro. Do subúrbio carioca, graduou-se em Desenho Industrial pela UFRJ e concluiu o doutorado com pesquisa sobre o tema design afirmativo. A pesquisa também resultou na série de entrevistas O que é animação negra? ${ }^{4}$ O professor do curso de Belas Artes da Universidade Federal Rural do Rio de Janeiro é reconhecido, principalmente, pela coleção Nana $\mathcal{E}$ Nilo, um projeto multimídia que nasce da literatura, vira animação e se desdobra em muitos outros. O projeto é fruto da sua amizade com Renato Noguera, professor de filosofia da UFRRJ. ${ }^{5}$

Agnaldo Timóteo, Alfredo Bosi, Anna Maria Martins, Antônio Bivar, Cassiano, Ciro Pessoa, Daniel Azulay, David Correa, Dona Neném, Edson Montenegro, Eva Wilma, Genival Lacerda, Ismael Ivo, Izael Caldeira, João Acaiabe, João Macacão, Leonardo Villar, Luis Sepúlveda, Martinho Lutero Galatti, Gésio Amadeu, José Mojica Marins (Zé do Caixão), Maria Lúcia Alvim, Miss Biá, Moraes Moreira, Naomi Munakata, Nelson Sargento, Nicette Bruno, Paulo José, Olga Savary, Orlando Drummond, Paulo Gustavo, Sérgio Mamberti, Sergio Sant'Anna, Tarcísio Meira, Ubirany Félix Do Nascimento, Uraci Micael Sales, entre tantos e tantas outras. A perda é imensa, mas maiores ainda são os seus legados na constelação da cultura brasileira.

Já que os termos em disputa provocam vestir verde e amarelo como sinal de patriotismo, pergunto: o que dizer de uma gente que se autoproclama nacionalista e não incentiva a cultura nacional, ao contrário, a desdenha? Em que medida, ao vestirem o "lindo pendão da esperança", não o usam para disfarçar as suas hipocrisias, propagando inverdades e ameaçando a conquista e a luta por democracia? A entrega do país com as vendas das empresas estatais revela a sujeira sob o manto canarinho: a reforma da Previdência, a reforma do Ensino Médio propalando a dualidade estrutural da educação para a classe dominante e a formação de mão de obra barata, perpetuando e aprofundando

3 IPCN: https://institutodepesquisadasculturasnegras.blogspot.com/ (Acessado: $01 \mathrm{Jul}$ 2021).

4 Acervo digital de cultura negra - Cultne. https://www.youtube.com/channel/UCjKjD0bztwIrsK16xODswIQ (Acessado: 01 Jul 2021).

5 Lopes, Sandro; Noguera, Renato et al. http://www.nanaenilo.com.br/index.html (Acessado: 01 Jul 2021). 
as desigualdades sociais, com a extinção do Ministério do Trabalho, o enxugamento do Estado, a permanente violência contra a classe trabalhadora.

Nós, desejo crer que a maioria do país, militantes pela vida, ainda cantamos e "cantamos porque os sobreviventes e nossos mortos querem que cantemos", seguimos cantando "porque o cruel não tem nome embora tenha nome seu destino" - com outras palavras, lamentam a fumaça da estátua do torturador histórico porque reconhecem nela o seu futuro. Cantamos e dançamos em volta dessas chamas que acinzentam o desejo pelo fim de uma era de torturas. Cantamos com as nossas estrelas e a nossa gente sempre vivas em nossas memórias, em seus legados. Por todas essas pessoas, tecendo um horizonte de expectativas com a sabedoria do MST: "nem um minuto de silêncio, mas toda a vida de luta".

\section{Referências}

Benjamin, Walter. (2012) Obras escolhidas - magia e técnica, arte e política: ensaios sobre literatura e história da cultura. São Paulo: Brasiliense.

Koselleck, Reinhart. (2006) Futuro passado: contribuição à semântica dos tempos históricos; tradução: Wilma Patrícia Maas, Carlos Almeida Pereira; revisão da tradução César Benjamin. Rio de Janeiro: Contraponto: Ed. PUC-Rio.

Nora, Pierre. (1993) Entre a memória e a história. A problemática dos lugares. Tradução: Yara Aun Khoury.
Proj.
História.
São Paulo,
(I0).
dez.
Disponível
em:

https://revistas.pucsp.br/revph/article/view/12101/8763/ 